2015-09

Home advantage? Decomposition across the freshwater-estuarine transition zone varies with litter origin and local salinity

Franzitta, G

http://hdl.handle.net/10026.1/4722

10.1016/j.marenvres.2015.07.012

MARINE ENVIRONMENTAL RESEARCH

Elsevier BV

All content in PEARL is protected by copyright law. Author manuscripts are made available in accordance with publisher policies. Please cite only the published version using the details provided on the item record or document. In the absence of an open licence (e.g. Creative Commons), permissions for further reuse of content should be sought from the publisher or author. 


\section{Home advantage? Decomposition across the freshwater-estuarine transition zone varies with litter origin and local salinity}

Giulio Franzitta ${ }^{a *}$, Mick E. Hanley ${ }^{\mathrm{b}}$, Laura Airoldi ${ }^{\mathrm{c}}$, Cecilia Baggini ${ }^{\mathrm{b}}$, David T. Bilton ${ }^{\mathrm{b}}$, Simon D. Rundle ${ }^{\mathrm{b}}$, Richard C. Thompson ${ }^{\mathrm{b}}$

${ }^{a}$ Department of Earth and Marine Sciences, University of Palermo, Via Archirafi 22, 90123 Palermo, Italy.

${ }^{\mathrm{b}}$ Marine Biology and Ecology Research Centre, Plymouth University, PL4 8AA Plymouth, Devon, United Kingdom.

${ }^{c}$ Department of Biological, Geological and Environmental Sciences, University of Bologna, Via S.Alberto 163, 48123 Ravenna, Italy.

*Corresponding author: giuliofranz@gmail.com 


\section{Abstract}

2 Expected increases in the frequency and intensity of storm surges and river flooding

3 may affect greatly the relative salinity of estuarine environments over coming decades.

4 In this experiment we used detritus from three contrasting environments (marine -

5 Fucus vesiculosus; estuarine Spartina anglica; terrestrial Quercus robur) to test the

6 prediction that the decomposition of the different types mof litter would be highest in

7 the environment with which they are associated. Patterns of decomposition broadly

8 fitted our prediction: Quercus detritus decomposed more rapidly in freshwater

9 compared with saline conditions while Fucus showed the opposite trend; Spartina

10 showed an intermediate response. Variation in macro-invertebrate assemblages was

11 detected along the salinity gradient but with different patterns between estuaries,

12 suggesting that breakdown rates may be linked in part to local invertebrate assemblages.

13 Nonetheless, our results suggest that perturbation of salinity gradients through climate

14 change could affect the process of litter decomposition and thus impact upon nutrient

15 cycling in esturine transition zones. Understanding the vulnerability of estuaries to

16 changes in local abiotic conditions is important given the need to better integrate coastal

17 proceses into a wider management framework at a time when coastalines are

18 increasingly threatened by human activities.

20 Keywords: decomposition; flooding; global change; invertebrate assemblage; litter bags. 


\section{Introduction}

24 Coastal ecosystems, including estuaries and salt marshes, face threats from various environmental stressors associated with global climate change (Nicholls, 2004; IPCC, 2012; Zappa et al., 2013, Wong et al., 2015). Increased sea level and more intense and

27 frequent storm surge events are likely to cause extensive shoreline erosion as well as

28 saltwater intrusion into coastal rivers (Bear et al., 1999; IPCC, 2012). However, coastal 29 protection is unlikely to be efficiently achieved simply by 'hard armouring' (Zanuttigh, 2011; Pontee and Parsons, 2010, 2012; Esteves, 2014). The innovative approaches for a sustainable coastal flood management incorporate natural processes and include the inundation of some coastal areas (Zanuttigh, 2011; Esteves, 2014; Hanley et al., 2014; Hoggart et al., 2014). Adopting integrated coastal defence approaches such as 'managed retreat' and 'no active intervention', however, requires an understanding of the ecological impact of floodings or other changes in flow regimes on recipient ecosystems and their functions (Pontee and Parsons, 2010; Bouma et al., 2014; Hoggart et al., 2014).

Decomposition is a fundamental process in the functioning of the estuarine ecosystem

39 (McLusky and Elliott, 2004), facilitating the recycling of nutrients and chemical

40 elements, and thereby sustaining important food chains and primary production

41 (Cummins et al., 1989; Graça, 2001; Quintino et al., 2009). The decomposition of

42 organic material in aquatic ecosystems proceeds in three sequential stages: leaching,

43 conditioning, and then fragmentation (Petersen and Cummins, 1974). Shortly after

44 falling into the water, leaf-litter rapidly loses mass due to the leaching of soluble organic

45 and inorganic constituents. This stage is followed by microbial colonization, causing numerous modifications to leaf condition and enhancing acceptability and colonization 
by macro-invertebrate detritivores responsible for the leaf fragmentation. The rate of this process depends on the physico-chemical characteristics of the leaf material, the local composition of both microbial and macrofaunal communities, and the abiotic environmental conditions of the environment (e.g. salinity, nutrients, water temperature, oxygen concentration, pH) (see Lopes et al., 2011 and references therein).

In estuaries, where salinity represents the main ecological factor defining habitat boundaries (Telesh and Khlebovich, 2010), the abiotic conditions gradually change along a gradient from marine to freshwater. Any significant changes in the intensity and frequency of seawater inflows into estuaries and rainfalls into rivers of the kind expected through climate change, are likely to modify the overall local abiotic conditions, with possible alteration of the decomposition process (Mendelssohn et al., 1999). Detritus from marine sources could be moved further inland and upstream through catchments (see Tate and Battaglia, 2013 for an example), whilst estuarine and marine systems might be expected to receive increased quantities of terrestrial leaf litter.

61 The consequence of such perturbation could be that detritus processing is due with local

62 mismatch between the salinity regime. Such mismatch would lead to direct effects on

63 breakdown rates, or indirectly affect decomposition via changes in the associated 64 detritivore assemblage, or a combination of both. To date, only few studies have explicitly examined how changes in local salinity and macrofauna affects detritus breakdown although those that do (Lettice et al., 2011; Lopes et al., 2011; Bierschenk et

67 al., 2012) report that decomposition rates varied according to salinity gradients and that 68 detritus originating from without the local system decomposed more slowly. Moreover, 69 the composition of the associated detritivore community changed along the salinity gradient (but see Lopes et al., 2013). These results suggest that detritus decomposes 
more effectively in the environmental conditions of its native habitat. Nevertheless, there has been no comparison of the decomposition of terrestrial, saltmarsh, and marine

73 litters across the range of salinities found in a typical estuary.

74 Here we report the results of a field experiment to investigate the breakdown rates of

75 terrestrial, saltmarsh, and marine derived detritus (respectively Quercus robur, Spartina

76 anglica and Fucus vesiculosus) across the salinity gradient in two neighbouring

77 estuaries in southern England. We also surveyed the composition of invertebrate

78 assemblages associated with the detritus in each habitat. In so doing, we provide the

79 first insights into the potential vulnerability of estuarine systems to shifts in local

80 conditions expected from climate-related changes in freshwater flooding and seawater

81 inundation events.

82

83 Materials and methods

\section{Study sites}

85 The experiment was undertaken in the estuaries of the rivers Yealm $\left(50^{\circ} 18.6^{\prime} \mathrm{N}\right.$,

$\left.86 \quad 04^{\circ} 4.2^{\prime} \mathrm{W}\right)$ and Erme $\left(50^{\circ} 18.3^{\prime} \mathrm{N}, 03^{\circ} 57.0^{\prime} \mathrm{W}\right)$, in South Devon, UK (Fig. 1). Both rivers

87 rise on Dartmoor flowing south for 16 and $20 \mathrm{~km}$ respectively before discharging into

88 Wembury and Bigbury bays. The estuaries of both rivers are characterized by similar

89 physical features: extension (about $6 \mathrm{~km}$ ); catchment area (Yealm $=55 \mathrm{~km}^{2}$, Erme $=43$

$\left.90 \mathrm{~km}^{2}\right)$; mean river flow discharge $\left(\right.$ Yealm $=1.7 \mathrm{~m}^{3} / \mathrm{s}$, Erme $\left.=1.9 \mathrm{~m}^{3} / \mathrm{s}\right)$; large tidal range 


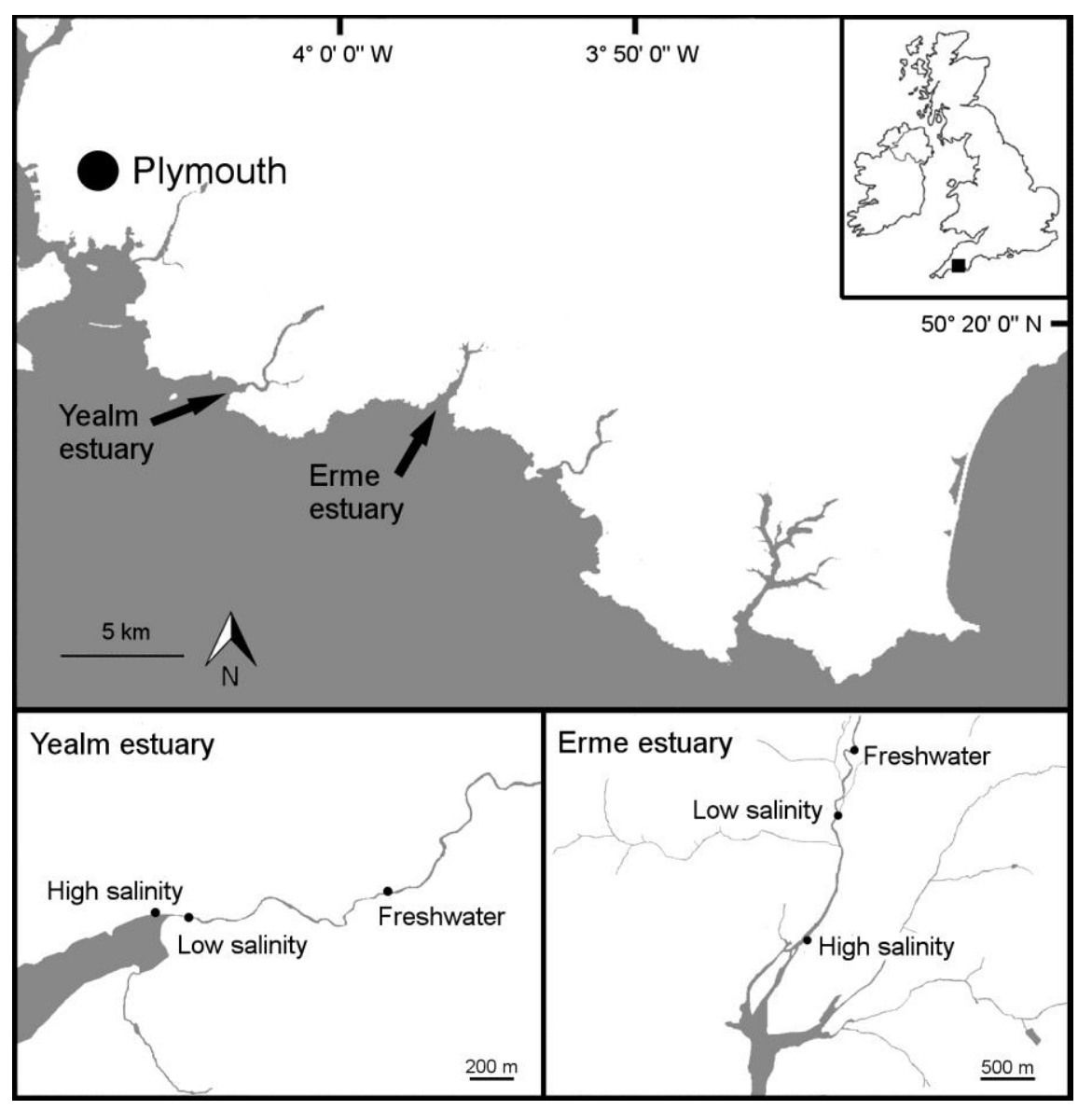

91 Fig. 1. Study site locations. Large map shows the position of the Yealm and erme estuaries in south

92 Devon. Smaller maps show the locations of with Freshwater, Low salinity and High salinity habitats in 93 each estuary: Yealm and Erme.

94 (4.7 m) and a full salinity range from marine to freshwater (Sheehan et al., 2010). In

95 both rivers, saltwater ingress into the freshwater zone is strongly limited by the presence 96 of weirs.

97 At each estuary, three habitats were selected along the salinity gradient, according to the

98 Venice System (1959) for the Classification of Estuarine Waters: 'freshwater' (limnetic);

99 'low salinity' water (mesohaline); 'high salinity' water (polyhaline). In the Yealm the

100 three habitats were located along $800 \mathrm{~m}$ stretch of estuary, whilst in the Erme the

101 passage from freshwater to high salinity occurred over a $2 \mathrm{~km}$ distance. The two

102 'freshwater' habitats $(\mathrm{Fw})$ were located at $600 \mathrm{~m}$ and $300 \mathrm{~m}$ upstream of a weir in the 
103 Yealm and Erme respectively (above the normal tidal limit - NTL), and were

104 characterized by wooded banksides dominated by broad-leaved trees. The two 'low

105 salinity' habitats (Lo) were located in areas equidistant between the NTL weirs and the

106 open coast, in sites where euryhaline species such as Ulva spp. indicated a brackish

107 regime. The riparian vegetation in these habitats were characterised by species typical

108 of upper saltmarsh vegetation. The two 'high salinity' habitats (Hi) were located in areas

109 dominated by marine macro-algae, and banksides featuring scattered trees and open

110 terrestrial vegetation.

111 Salinity was recorded continuously by loggers submerged and anchored to the river bed

112 for 4 weeks, from end of May to June 2010 (i.e. during the decomposition experiment).

113 The mean salinity values (expressed as Practical Salinity Unit, \pm standard deviation), at

114 the three habitats in each river (from freshwater to low salinity and high salinity) were:

$1150.0( \pm 0.0), 17.6( \pm 2.2), 23.0( \pm 1.8)$, in the Yealm; and $0.0( \pm 0.0), 12.4( \pm 3.0), 20.1( \pm$

116 3.1) in the Erme.

\section{Experimental procedure}

118 The decomposition experiment was run using 3 species particularly abundant in the

119 three study habitats: these were (respectively) the tree Quercus robur L. (Fagaceae); the

120 grass Spartina anglica C. E. Hubb. (Poaceae), and the fucoid alga Fucus vesiculosus L.

121 (Fucaceae). Naturally dehisced leaves or laminae from the three species were collected

122 in May 2010 from woods adjacent to the freshwater sites (Quercus), salt marshes near

123 the low salinity sites (Spartina), and the inter-tidal in the area of high salinity sites

124 (Fucus) within the catchment of both rivers. The leaf material for the experiment was

125 randomly selected from the collection sites and subsequently oven-dried to constant 
weight $\left(60^{\circ} \mathrm{C}\right.$ for 72 hours $)$.

127 Since detritus from the three sources had different dry densities, we prepared litter bags

128 with different weights but similar volumes in order to offer comparable surfaces for

129 detritivore colonization. The litter bags (nylon cloth, 100 x $100 \mathrm{~mm}, 5 \mathrm{~mm}$ mesh size;

130 Bärlocher 2005) were half filled with dried detritus, (corresponding to $5 \mathrm{~g}$ of Quercus, 8

$131 \mathrm{~g}$ of Spartina and $12 \mathrm{~g}$ of Fucus). In the case of Spartina the leaves were cut into $8 \mathrm{~cm}$

132 long fragments (excluding the basal and apical parts). The $5 \mathrm{~mm}$ mesh size was chosen

133 to allow colonization by macroinvertebrates yet at the same time reduce the potential for

134 detritus loss due to fragmented litter falling out of the bags (Quintino et al., 2009). Four

135 replicate bags for each species were deployed at each of the three habitats (Fw, Lo, Hi)

136 at each of the two estuaries (Yealm, Erme). The bags were attached to ropes anchored to

137 the river bed by bags of pebbles and steel pegs hammered into the sediment, to prevent

138 occasional emersion in low tides and limit abrasion. We exposed the detritus for 38 days

139 (late May to late June 2010), based on decomposition rates estimated from previous

140 studies (Sangiorgio et al., 2008; Quintino et al., 2009). After this time, the litter bags

141 were retrieved and preserved in plastic bags containing $70 \%$ alcohol. The detritus was

142 washed to remove sediment, dried in an oven at $60^{\circ} \mathrm{C}$ for 72 hours and reweighed.

143 Macro-invertebrates were separated from the sediment with a $500 \mu \mathrm{m}$ mesh size,

144 identified at the lowest possible taxonomic level and counted.

\section{Data analyses}

146 Weight loss for each litter species was calculated as percentage according to the

147 following equation: $\% \mathrm{~L}=\left(\mathrm{W}_{0}-\mathrm{W}_{\mathrm{t}}\right) / \mathrm{W}_{0} \times 100$, where $\mathrm{W}_{0}$ is the original dry weight of the

148 litter and $\mathrm{W}_{\mathrm{t}}$ was the dry weight remaining after 38 days (Petersen and Cummins, 1974). 
149 Furthermore, in order to compare the decomposition rates for Quercus, Fucus and

150 Spartina with those described in other studies, weight loss was also calculated

151 according to the decay exponential function $\mathrm{k}=-(1 / \mathrm{t}) \times \ln \left(\mathrm{W}_{\mathrm{t}} / \mathrm{W}_{0}\right)$ (Petersen and

152 Cummins, 1974).

153 Differences in relative weight loss between litter species, habitats, and estuaries were

154 tested via a three-way ANOVA, incuding 3 othogonal factors "Estuary" (Es, two levels:

155 Y - Yealm, E - Erme, random), “Detritus" (De, three levels: Quercus, Spartina and

156 Fucus, fixed) and "Habitat" (Ha, three levels: Fw - Freshwater, Lo - Low salinity, Hi -

157 High salinity, fixed). There were four replicates for each factor combination. ANOVA

158 was carried out using SPSS v.18 package. Prior to ANOVA, the data were examined for

159 normality and homogeneity of variance using Levene's test, and Arcsine (\%)

160 transformed to meet the required assumptions of homogeneity of variance. Tukey's

161 HSD test was used to perform pairwise comparison for significant differences.

162 Differences in the multivariate structure of macrofaunal, detritivore assemblages as a

163 function of different detritus types, habitat, and estuary location were assessed via a

164 three-way PERMANOVA using the same logic described above. The analysis was

165 performed with PERMANOVA + add on package for the PRIMER v6 software (Clarke

166 and Warwick, 2001; Anderson et al., 2008). Data were log transformed to preserve

167 information on relative abundance of each species, while reducing differences in scales

168 among variables (Clarke and Warwick, 2001), and used to build a matrix of Bray-Curtis

169 similarity coefficients. For the analysis, 9999 unrestricted random permutations of

170 residuals were used to generate p-values. For some terms in the analysis, there were not

171 enough permutable units to get a reliable permutation test, so a p-value was obtained

172 using a Monte Carlo random sample from the asymptotic permutation distribution 
173 (Anderson and Robinson, 2003).

174 A non-metric multidimensional scaling (NMDS) ordination, calculated on the same

175 Bray-Curtis similarity matrix, was used to visualize multivariate patterns of distribution

176 of the macrofaunal assemblages (Clarke and Warwick 2001). Given the large number of

177 replicates $(n=72)$, we plotted centroids for the combined factor Estuary-Habitat. The

178 similarity percentage routine (SIMPER) was used to highlight which taxa provided the

179 largest contribution to dissimilarities between categories (Clarke and Warwick, 2001).

180

$181 \quad$ Results

182 Detritus breakdown

183 All litter bags were successfully recovered. Biomass loss through the 38 days of

184 exposure varied considerably according to detritus type and position along the estuarine

185 salinity gradient. Overall, Quercus litter breakdown was slowest, with weight loss never 186 exceeding $42 \%$, whereas Fucus litter decomposed fastest, up to $95 \%$ weight loss over

187 the 38 days exposure (Fig. 2a). Detritus from terrestrial vegetation and marine fucoid

188 macroalgae showed the opposite trend in breakdown rate along the salinity gradient

189 (Figs 2a; 2b). Significant differences were detected between habitats for both Quercus

190 and Fucus (Table 1). Biomass loss of Quercus litter declined from Fw $(41.3 \% \pm 0.03)$

191 to Lo $(28.4 \% \pm 0.04)$ and Hi $(19.2 \% \pm 0.02)$ habitats (Fig. 2a). In contrast, the biomass

192 loss of Fucus litter was lower in Fw $(80.5 \% \pm 0.02)$ with respect to Lo $(95.4 \% \pm 0.01)$

193 and $\mathrm{Hi}(95.2 \% \pm 0.01)$ habitats (Fig. 2a). The trend in breakdown rate of Quercus vs

194 Fucus along the gradient was consistent between estuaries (Fig. 3). 
195 Biomass loss for Spartina litter ranged from $61.8 \% \pm 0.03$ in $\mathrm{Fw}$ to $50.2 \% \pm 0.03$ in

$196 \mathrm{Hi}$, without significant differences between habitats (Table 1; Fig. 2a). However, we

197 found different trends in breakdown rate of Spartina between estuaries. In effect, the

198 biomass loss of Spartina reach very different value among the low salinity habitats of

199 the two estuaries. In the Yealm the biomass loss among habitats was the higher in Lo,

200 whereas in the comparison among habitat in the Erme the biomass loss was the lower on
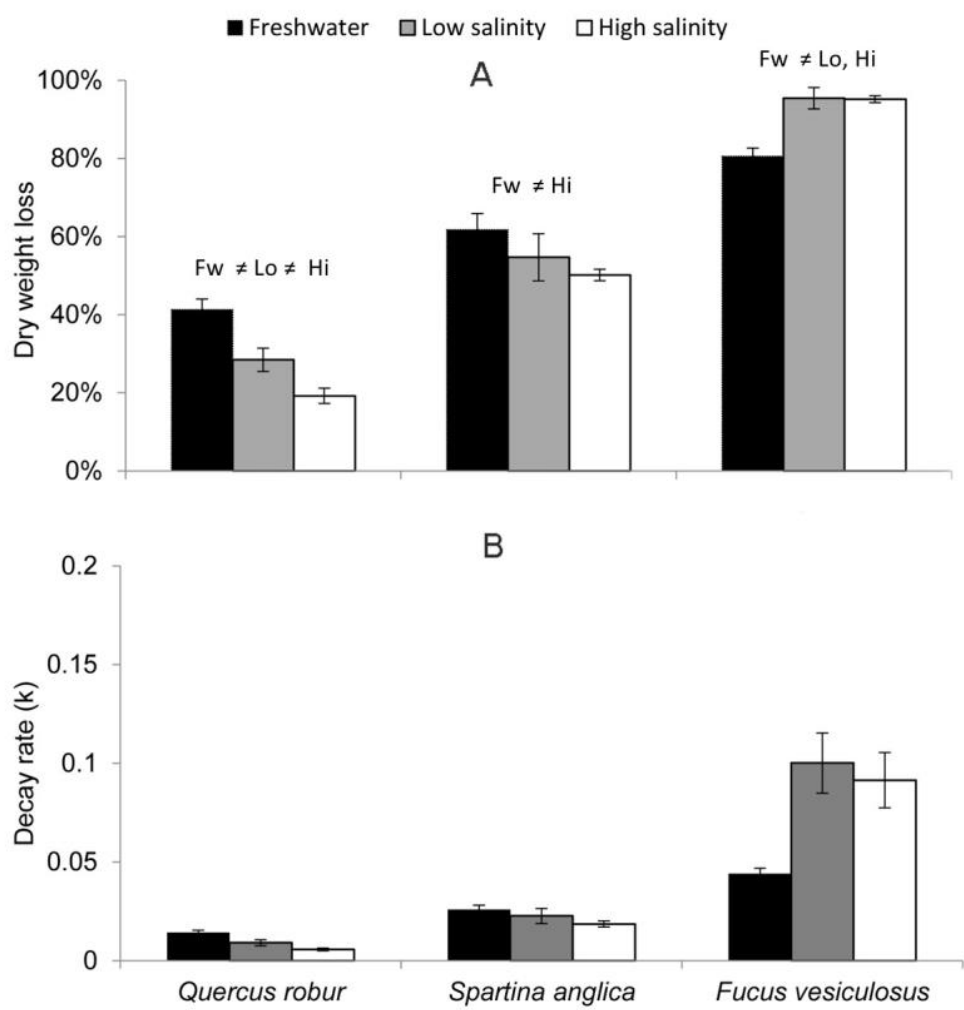

201 Lo (Fig. 3).

202 Fig. 2. Leaf litter breakdown of the three detritus types at Freshwater ( $F w)$, Low salinity (Lo) and High 203 salinity (Hi) habitats, indicated by: A) dry weight mass loss with superscript significant differences 204 among habitats for each detritus type; B) decay rates. Data are averages \pm 1 S.E. $(n=4)$. 
De $x$ Ha. Prior to ANOVA, the data were arcsine transformed in order to meet assumption of homogeneity of variance. Significance (Sign.): $*=p<0.05 ; * *=p<0.01, * * *=p<0.001, n s=$ not significant.

\begin{tabular}{|c|c|c|c|c|c|c|c|c|}
\hline Source & df & MS & $\mathrm{F}$ & Sign. & $\begin{array}{l}\text { Pairwise } \\
\text { comparisons }\end{array}$ & Quercus & Spartina & Fucus \\
\hline Es & 1 & 0.174 & 0.789 & ns & Fw vs Lo & * & ns & *** \\
\hline $\mathrm{De}$ & 2 & 4.717 & 63.721 & * & $\mathrm{Fw}$ vs $\mathrm{Hi}$ & $* * *$ & ** & $* * *$ \\
\hline $\mathrm{Ha}$ & 2 & 0.026 & 0.164 & ns & Lo vs $\mathrm{Hi}$ & * & ns & ns \\
\hline $\mathrm{Es} \times \mathrm{De}$ & 2 & 0.074 & 6.788 & ns & & & & \\
\hline Es $\times \mathrm{Ha}$ & 2 & 0.157 & 14.384 & * & & Fw & Lo & $\mathrm{Hi}$ \\
\hline $\mathrm{De} \times \mathrm{Ha}$ & 4 & 0.226 & 20.738 & ** & Quercus vs Spartina & $* \star *$ & *** & *** \\
\hline $\mathrm{Es} \times \mathrm{De} \times \mathrm{Ha}$ & 4 & 0.011 & 2.094 & ns & Quercus vs Fucus & $\star \star \star *$ & $\star * \star$ & $\star \star *$ \\
\hline Residuals & 54 & 5 & & & Spartina vs Fucus & $* * *$ & $* * *$ & $* \star *$ \\
\hline
\end{tabular}

\section{Macro-faunal distribution}

215 The macrofaunal assemblages comprised 35 taxa, among which the most abundant were

216 Gammarus zaddachi (Amphipoda) and chironomid larvae (Diptera) at 50.4\% and

$21728.6 \%$ of the total abundance respectively. G. zaddachi dominated Lo and Hi habitats,

218 whereas chironomids were abundant in Fw. The third most abundant group were

219 hydrobiid gastropods (7.3\%). Other common taxa included the juvenile crustaceans

220 Carcinus sp. (Decapoda) and Jaera sp. (Isopoda) and the juvenile insects belonging to

221 the families Leuctridae (Plecoptera), Ephemerellidae (Ephemeroptera) and

222 Lepidostomatidae (Trichoptera).

223 Mean taxon richness of macrofauna was higher in Fw (11.2 \pm 1.4$)$ compared to Lo (3.9

$224 \pm 1.4)$ and $\mathrm{Hi}(4.0 \pm 0.9)$. This pattern was largely driven by the diversity of families of

225 insects in Fw and the dominance of Gammarus zaddachi in Lo and Hi. There were also

226 differences in the numbers of individuals and in dominance patterns between the two

227 estuaries: in the Yealm we recorded 11,791 individuals, most of which were Gammarus 228 zaddachi (63.1\%) and Chironomidae (21.2\%); whereas in the Erme we collected only 
2294,358 individuals but with higher and lower representation of Chironomidae (48.8\%)

230 and Gammarus zaddachi $(16.1 \%)$ respectively.

231 Multivariate analyses revealed little variation in the macro-invertebrate assemblages

232 among detritus species within habitats. The NMDS plot shows variation in assemblages

233 between habitats along the salinity gradient. While Fw habitats of the two estuaries were

234 clustered together, Lo and Hi were clustered together within rather than across habitats

235 (Fig. 3). The PERMANOVA test failed to detect any significant differences between

236 detritus species in the same habitat site, but did show that invertebrate assemblages

237 differed between habitats for each detritus species (De x Ha, $\mathrm{p}(\mathrm{MC})=0.0166)$. However

238 the pattern was not consistent between the two estuaries (Table 2). The post-hoc

239 PERMANOVA test, performed for each estuary separately, confirmed that that

240 invertebrate assemblages populating each detritus type differed among habitats (Table

$2412)$.

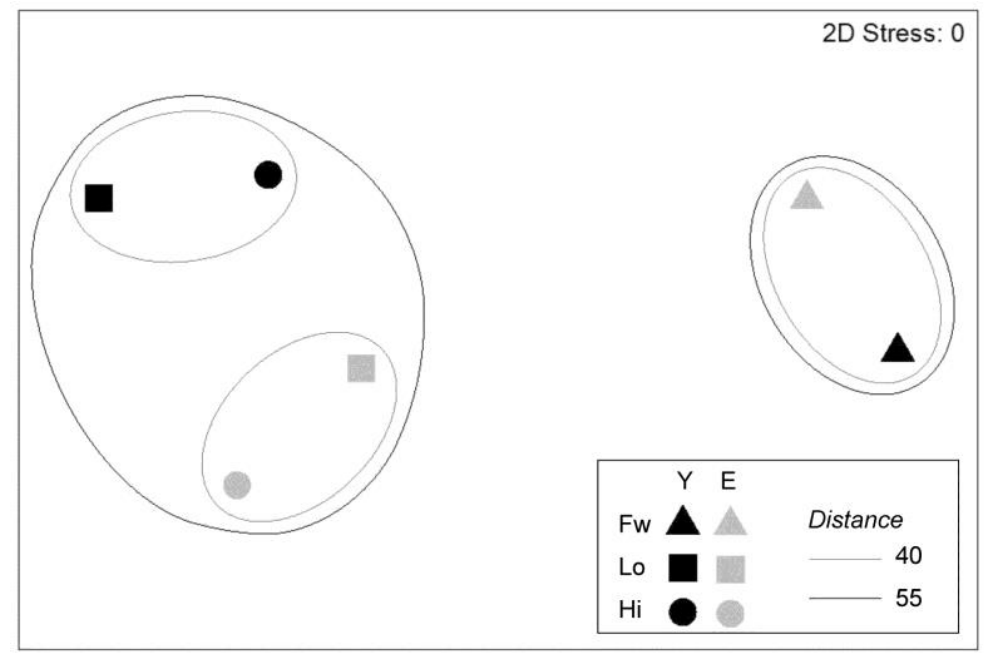

242 Fig. 3. NMDS ordinations of centroids for estuaries (Yealm versus Erme) and habitats (Fw = Freshwater,

243 Lo = Low salinity, Hi = High salinity; Estuaries: $Y=$ Yealm, $E=$ Erme). Lines show groupings derived 244 using cluster analysis. 
246 Table 2. PERMANOVA (35 variables, log-transformed data) showing changes in macrofaunal

247 assemblages in relation to Estuary (Yealm vs Erme, random factor), Detritus type (Quercus, Spartina and 248 Fucus, fixed factor) and Habitat (Freshwater $=F w$, Low salinity water $=$ Lo and High salinity water $=$

$249 \mathrm{Hi}$, fixed factor) with pairwise comparisons for the term De $x$ Ha for pairs of levels of factor 'Ha' at each

\begin{tabular}{|c|c|c|c|c|c|c|c|c|}
\hline Source & df & MS & Pseudo-F & Sign. & $\begin{array}{l}\text { Pairwise } \\
\text { comparisons }\end{array}$ & Quercus & Spartina & Fucus \\
\hline Es & 1 & 17652 & 37.001 & $* * *$ & Yealm & & & \\
\hline $\mathrm{De}$ & 2 & 3237.9 & 2.088 & ns & Fw vs Lo & $* * *$ & $* * *$ & $* * *$ \\
\hline $\mathrm{Ha}$ & 2 & 40553 & 3.8265 & ns & $\mathrm{Fw} v s \mathrm{Hi}$ & $* * *$ & $* * *$ & $* \star * *$ \\
\hline Es $\times \mathrm{De}$ & 2 & 1550.7 & 3.2505 & $* * *$ & Lo vs $\mathrm{Hi}$ & ** & ** & ** \\
\hline Es $\times \mathrm{Ha}$ & 2 & 10598 & 22.215 & $* * *$ & Erme & & & \\
\hline $\mathrm{De} \times \mathrm{Ha}$ & 4 & 1573.1 & 2.8695 & * & Fw vs Lo & $* * *$ & ** & ** \\
\hline Es $\times \mathrm{De} \times \mathrm{Ha}$ & 4 & 584.2 & 1.1491 & $\mathrm{~ns}$ & Fw vs $\mathrm{Hi}$ & $* * *$ & ** & $* * *$ \\
\hline Residuals & 54 & 477.07 & & & Lo vs Hi & * & * & * \\
\hline
\end{tabular}

estuary. Significance (Sign.): $*=p<0.05 ; * *=p<0.01,{ }^{* * *}=p<0.001, n s=$ not significant.

253 SIMPER analysis (Table 3) showed that the Fw habitats of the two estuaries were

254 characterized by a greater representation of Chironomidae compared to both Lo and Hi

255 habitats and by the almost exclusive occurrence of Gammarus pulex and Leuctridae,

256 Lepidostomatidae, Ephemerellidae, and Elmidae larvae. Conversely, Lo and Hi habitats

257 were dominated by Gammarus zaddachi, a species particularly abundant in the Yealm estuary. 
260 Table 3. SIMPER showing the species most contributing to the Dissimilarities (Diss) detected in

261 macrofaunal assemblages between different estuaries (Yealm, Erme) and habitats (Fw = Freshwater; Lo

$262=$ Low salinity; $\mathrm{Hi}=$ High salinity). $J=$ Juvenile.

\begin{tabular}{|c|c|c|c|c|}
\hline \multirow{2}{*}{$\begin{array}{l}\text { Taxa } \\
\text { Average diss }=56.54\end{array}$} & \multicolumn{2}{|c|}{ Mean abundance } & \multirow[t]{2}{*}{ Diss/SD } & \multirow{2}{*}{$\begin{array}{l}\text { Contribution } \\
\text { to diss (\%) }\end{array}$} \\
\hline & Yealm & Erme & & \\
\hline Gammarus zaddachi & 3.22 & 1.74 & 0.8 & 17.96 \\
\hline Hydrobiidae & 1.25 & 1.56 & 1.25 & 13.1 \\
\hline Chironomidae $(\mathrm{J})$ & 2.99 & 3.14 & 1.1 & 11.97 \\
\hline Carcinus sp. & 0 & 0.93 & 0.91 & 8.51 \\
\hline Jaera sp. & 0.12 & 0.99 & 0.84 & 8.15 \\
\hline Carcinus sp. (J) & 0 & 0.86 & 0.84 & 7.3 \\
\hline Oligochaeta & 0.99 & 0.4 & 0.5 & 3.63 \\
\hline Average diss $=85.85$ & Fw & Lo & & \\
\hline Gammarus zaddachi & 0 & 3.91 & 2.04 & 14.2 \\
\hline Chironomidae $(\mathrm{J})$ & 4.9 & 1.57 & 1.86 & 12.57 \\
\hline Hydrobiidae & 205 & 1.31 & 1.62 & 9.92 \\
\hline Leuctridae $(\mathrm{J})$ & 2.3 & 0 & 1.57 & 8.18 \\
\hline Ephemerellidae (J) & 1.94 & 0 & 2.05 & 6.84 \\
\hline Lepidostomatidae $(\mathrm{J})$ & 1.96 & 0.07 & 2.02 & 6.84 \\
\hline Gammarus pulex & 1.75 & 0 & 1.94 & 6.12 \\
\hline Elmidae $(\mathrm{J})$ & 1.61 & 0.03 & 1.84 & 5.7 \\
\hline Average diss $=81.34$ & $\mathrm{Fw}$ & $\mathrm{Hi}$ & & \\
\hline Gammarus zaddachi & 0 & 3.52 & 2.04 & 13 \\
\hline Hydrobiidae & 2.5 & 0.4 & 1.43 & 8.75 \\
\hline Chironomidae $(\mathrm{J})$ & 4.9 & 2.74 & 1.73 & 8.49 \\
\hline Leuctridae $(\mathrm{J})$ & 2.3 & 0 & 1.62 & 8.31 \\
\hline Lepidostomatidae (J) & 1.96 & 0 & 2.15 & 7.34 \\
\hline Ephemerellidae $(\mathrm{J})$ & 1.94 & 0 & 2.11 & 7.05 \\
\hline Gammarus pulex & 1.75 & 0 & 1.94 & 6.34 \\
\hline Elmidae $(\mathrm{J})$ & 1.61 & 0 & 1.93 & 5.91 \\
\hline Carcinus sp. & 0 & 1.03 & 0.8 & 4.04 \\
\hline Asellus sp. & 1.06 & 0 & 0.86 & 3.91 \\
\hline Average diss $=45.23$ & Lo & $\mathrm{Hi}$ & & \\
\hline Chironomidae $(\mathrm{J})$ & 1.57 & 2.74 & 1.22 & 27.77 \\
\hline Gammarus zaddachi & 3.91 & 3.52 & 1.19 & 23.89 \\
\hline Hydrobiidae & 1.31 & 0.4 & 0.81 & 9.79 \\
\hline Jaera sp. & 1.03 & 0.63 & 0.88 & 8.85 \\
\hline
\end{tabular}

\section{Discussion}

266 In this study, we found that each detritus type decomposed at the highest rate in salinity

267 conditions typical of its native habitat, and that major differences among associated

268 detritivore assemblages were apparent according to habitat. So-called 'home field 
advantage' is well understood for the decomposition process in terrestrial habitats

270 (Milcu and Manning, 2011; Jewell et al., 2015), but less well described for aquatic

271 systems. Given the likely susceptibility of estuarine transitions to rapid and acute shifts

272 in environmental conditions with storm surges and freshwater flooding events, our

273 results show that concomitant variation in detritus distribution and salinity regimes

274 could alter greatly the normal processes of detritus decomposition. Such changes are

275 manifest as a consequence of direct shifts in local abiotic conditions, and the indirect

276 effects of changes in local detritivore assemblages.

277 In a recent bioassay, Bierschenk et al. (2012), reported more rapid breakdown rate of

278 cotton materials in freshwater than mid-estuary, or near-marine habitats, noting that the

279 decomposition response to variation in salinity depends on the type of material. Our

280 results corroborate and extend these observations in that we demonstrate 'home-field

281 advantage' for detritus decomposition along estuarine gradients. Quercus litter

282 decomposed much more rapidly in 'freshwater' than in 'high salinity' habitats while

283 Fucus litter displayed the opposite trend. Lopes et al. (2011) reported a similar pattern

284 of decomposition for F. vesiculosus, although the relatively rapid breakdown of Fucus

285 litter in all environments is unsurprising given its low lignin and cellulose content and

286 relatively high $\mathrm{N}$-content compared to vascular plants (Tenore and Hanson, 1980).

287 Indeed there may be a general tendancy for high quality leaf material to experience

288 faster consuption by invertebrates (Fernandes et al., 2015). The more fibrous leaves of

289 Quercus spp. naturally have relatively slow decomposition rates (Petersen and

290 Cummins, 1974) compared with saltmarsh plants or marine macro-algae.

291 While there is a surprising paucity of literature detailing the breakdown of saltmarsh

292 halophytes and marine macro-algae in temperate freshwater ecosystems, the few studies 
293 that have examined the issue report similar (Castela et al., 2008), or slower (Lopez et

294 al., 2001), decomposition rates to those recorded here for Spartina. Spartina litter is

295 high in recalcitrant lignins, but despite this Spartina spp. have a broad range of

296 decomposition rates, influenced by position in the marsh and hydrological regime

297 (Marinucci, 1982; Kirwan et al., 2013). As with Quercus and Fucus, it seems that

298 Spartina may be degraded faster in areas it naturally occupies (i.e. 'low salinity' habitat),

299 but interestingly this was only observed in the Yealm estuary. The observed difference

300 in Spartina decomposition between estuaries might be related to local variations in flow

301 regimes, which can influence decompositional process via mechanical breakdown,

302 microbial colonization and oxygen concentration (Menéndez et al., 2001). The 'low

303 salinity' habitat of the Yealm was characterized by fast running water and a rocky bed,

304 but the corresponding habitat in the Erme had slower flow and fine-grained sediments

305 (Franzitta personal observation). In the latter, lower oxygen concentration may have

306 limited decomposer activity (Chauvet, 1997).

307 Although we cannot rule out the possibility that observed species-specific variation in

308 litter decomposition between habitats was linked to microbial diversity, abundance, and

309 activity (Roache et al., 2006; Martins et al., 2012), we did note (estuary-specific)

310 variation in macro-invertebrate assemblages along the salinity gradient. Nonetheless for

311 both estuaries the structure and composition of the detritivore community populating the

312 'low salinity' and 'high salinity' sites were consistent, a consequence of the over-riding

313 dominance of the amphipod, Gammarus zaddachi. Gammarus is a highly opportunistic

314 feeder (considered a facultative shredder by Cummins and Klug, 1979), but given the

315 choice between different food items exhibits a certain degree of selectivity (Friberg and

316 Jacobsen, 1994). In both saline habitats, the differences in breakdown rate between the 
317 marine-derived Fucus litter and Quercus could suggest that the absence of a more

318 functionally diverse invertebrate assemblage (that includes shredders, scrapers,

319 collectors and herbivores) slowed the decomposition of recalcitrant terrestrial detritus

320 compared to freshwater habitats. Indeed the presence of shredders, principally from the

321 stonefly family Leuctridae and the caddisfly families Leptoceridae, Limnephilidae and

322 Sericostomatidae, in freshwater, and their ability to hydrolyze and assimilate the

323 refractory molecules of lignin, cellulose and hemicellulose (Cummins et al., 1989) is

324 likely responsible for the faster breakdown of the sclerophyll leaves of Quercus robur.

325 However, the role played by macroinvertebrates in the decomposition process remains

326 uncertain. Similar to our study, Lopes et al. (2013) report few differences in invertebrate

327 assemblages associated with Fucus vesiculosus and Phragmites australis along an

328 estuarine gradient, and concluded that macroinvertebrates do not influence leaf litter

329 decomposition.

330 Our's is the first study to report how one key aspect of ecosystem functioning along

331 estuarine transitions might respond to expected changes in the frequency and severity of

332 freshwater flooding and seawater inundation events. Storms surges are likely to both

333 carry large amounts of marine derived detritus further inland and/or alter the salinity of

334 freshwater habitats, while increased river discharge may have the opposite effect (more

335 terrestrial material carried downsteam with freshwater pulses). Our results indicte that

336 these shifts could greatly impact litter decomposition along the estauarine transition,

337 partly because of shifts in water salinity, but also because in-situ detritivore

338 communities are ill equipped to cope with 'alien' litter. More generally therefore, we

339 suggest that acute changes in conditions as a result of phenomena associated with

340 anthropogenic climate change may influence the structure and function of estuarine 
341 ecosystems and with it their likely resilience to further environmental perturbation and

342 role in coastal protection.

343

344 Acknowledgments

345 We thank Chris McCullough, Elena Righetti, Jana Rajnohova, Sabrina Heiser, Alex

346 Fraser, Ann Torr, Richard Ticehurst and Roger Haslam for technical support and two

347 anonymous referees for comments on an earlier version of this MS. This research was

348 supported by the THESEUS project (EU FP/7, contract number 244104; Innovative

349 technologies for safer European coasts in a changing climate) and by a Marco Polo

350 grant of Bologna University to G.F. We are most grateful to Rodney Bastard and

351 Anthony Mildmay-White for access to the Yealm and Erme respectively.

352 
353

\section{References}

Anderson, M.J., Gorley, R.N., Clarke, K.R., 2008. PERMANOVA for PRIMER: Guide to Software and Statistical Methods. PRIMER-E, Plymouth, UK

Anderson, M.J., Robinson, J., 2003. Generalized discriminant analysis based on distances. Australia and New Zealand Journal of Statistics 45, 301-318.

Bärlocher, F., 2005. Leaf mass loss estimated by litter bag technique. In `Methods to Study Litter Decomposition: A Practical Guide’' (Eds M. A. S. Graça, F. Bärlocher and M. O. Gessner.) pp. 115-120. (Springer: Dordrecht, Netherlands).

Bierschenk, A.M., Savage, C., Townsend, C.R., Matthaei, C.D., 2012. Intensity of land use in the catchment influences ecosystem functioning along a freshwatermarine continuum. Ecosystems 15, 637-651.Bouma, T.J., van Belzen, J., Balke, T., Zhu, Z., Airoldi, L., Blight, A.J., Davies, A.J., Galvan, C., Hawkins, S.J., Hoggart, S.P.G., Lara, J.L., Losada, I.J., Maza, M., Ondiviela, B., Skov, M.W., Strain, E.M., Thompson, R.C., Yang, S., Zanuttigh, B., Zhang, L., Herman, P.M.J., 2014. Identifying knowledge gaps hampering application of intertidal habitats in coastal protection: Opportunities \& steps to take. Coastal Engineering $87,147-157$.

Castela, J., Ferreira, V., Graça, M.A.S., 2008. Evaluation of stream ecological integrity using litter decomposition and benthic invertebrates. Environmental Pollution $153,440-449$.

Chauvet, E., 1997. Leaf litter decomposition in large rivers: the case of the River Garonne. Limnetica 13, 65-70.

Clarke, K.R., Warwick, R.M., 2001. 'Change in marine communities: an approach to statistical analysis and interpretation', 2nd Edn. (PRIMER-E: Plymouth, UK.) 
377 Cummins, K. W. and Klug, M. J. (1979). Feeding ecology of stream invertebrates. Annual Review of Ecology and Systematics 10, 147-172.

Cummins, K.W., Wiltzbach, M.A., Gates, D.M., Perry, J.B., Taliaferro, W.B., 1989. Shredders and riparian vegetation: leaf letter that falls into streams influences communities of stream invertebrates. BioScience 39, 24-31.

382 Esteves, L.S., 2014. Managed realignment: a viable long-term coastal management strategy? SpringerBriefs in Environmental Science. New York: Springer.

Fernandes, I., Duarte, S., Cássio, F., Pascoal, C., 2015. Plant litter diversity affects invertebrate shredder activity and the quality of fine particulate organic matter in streams. Marine and Freshwater Research 66, doi.org/10.1071/MF14089.

Friberg, N., Jacobsen, D., 1994. Feeding plasticity of 2 detrivore-shredders. Freshwater Biology 32, 133-142.

Graça, M.A.S., 2001. The role of invertebrates on leaf litter decomposition in streams a review. International Review of Hydrobiology 86, 383-393.

Hanley, M.E., Hoggart, S.P.G., Simmonds, D.J., Bichot, A., Colangelo, M.A., Bozzeda, F., Heurtefeux, H., Ondiviela, B., Ostrowski, R., Recio, M., Trude, R., Zawadzka-Kahlau, E., Thompson, R.C., 2014. Shifting sands? Coastal protection by sand banks, beaches and dunes. Coastal Engineering 87, 136-146.

Hoggart, S.P.G., Hanley, M.E., Parker, D.J., Simmonds, D.J., Franklin, E.L.,White A.C., Bilton, D.T., Rundle, S.D., Penning-Rowsell, E.C., Trifonova, E., Vergiev, S., Filipova-Marinova, M., Kotsev, I., Thompson, R.C., 2014. The consequences of doing nothing: The effects of seawater flooding on coastal zones. Coastal Engineering 87, 169-182. 
IPCC, 2007. 'The physical science basis contribution of working group I the fourth assessment report of the Intergovernmental Panel on Climate Change'. (Cambridge University Press: Cambridge, UK.)

Intergovernmental Panel on Climate Change (IPCC), 2012. Summary for policymakers, in Managing the Risks of Extreme Events and Disasters to Advance Climate Change Adaptation, edited by C. Field et al., pp. 1-19, Cambridge Univ. Press, Cambridge, UK.

Jewell, M.D., Shipley, B., Paquette, A., Messier, C., Reich, P.B. 2015. A traits-based test of the home-field advantage in mixed-species tree litter decomposition. Annals of Botany 116: doi:10.1093/aob/mcv105

Kirwan, M.L., Langley, G.A., Guntenspergen, G.R., Megonigal, J.P., 2013. The impact of sea-level rise on organic matter decay rates in Chesapeake Bay brackish tidal marches. Biogeosciences 10, 1869-1876.

Lettice, S., Jansen, M.A.K., Chapman, D.V., 2011. Differential decomposition patterns of marine and terrestrial biomass in a coastal lagoon. Geo-Eco-Marina 17, 5158.

Lopes, M.L., Martins, P., Rodrigues, A.M., Quintino, V., 2013. Macroinvertebrates communities associated with the decomposition of Phragmites australis and Fucus vesiculosus in transitional systems. Journal of Sea Research 83, 72-82.

Lopes, M.L., Martins, P., Ricardoa, F., Rodrigues, A.M., Quintino, V., 2011. In situ experimental decomposition studies in estuaries: A comparison of Phragmites australis and Fucus vesiculosus. Estuarine, Coastal and Shelf Science 92, 573580. 
423 Marinucci, A.C., 1982. Trophic importance of Spartina alterniflora production and decomposition to the marsh-estuarine ecosystem. Biological Conservation 22, $35-58$.

Martins, P., Lopes, M.L., Rodrigues, A.M., Gomes, N.C., Quintino, V., 2012. Bacterial communities associated with the decomposition of Fucus vesiculosus in transitional waters. Estuarine, Coastal and Shelf Science 110, 116-124.

McLusky, D.S., Elliott, M., 2004. The Estuarine Ecosystem. Ecology, Threats and Management, 3rd Edn. (Oxford University Press: Oxford, UK.).

Mendelssohn, I.A., Sorrell, B.K., Brix , H., Schierup, H-H., Lorenzen, B., Maltby, E., 1999. Controls on soil cellulose decomposition along a salinity gradient in a Phragmites australis wetland in Denmark. Aquatic Botany 64, 381-398.

Menéndez, M., Martinez, M., Hernàndez, O., Comìn, F. A., 2001. Comparison of leaf decomposition in two Mediterranean rivers: a large eutrophic river and an oligotrophic stream (S Catalonia, NE Spain). International Review for Hydrobiology 86, 475-486.

Milcu, A., Manning, P., 2011. All size classes of soil fauna and litter quality control the acceleration of litter decay in its home environment. Oikos 120, 1366-1370.

Nicholls, R.J., 2004. Coastal flooding and wetland loss in the $21^{\text {st }}$ century: changes under the SRES scenarios. Global Environmental Change 14, 69-86.

442 Petersen, R.C., Cummins, K.W., 1974. Leaf processing in a woodland stream. Freshwater Biology 4, 343-368.

444 Pontee N.I,, Parsons, A., 2010. A review of coastal risk management in the UK. Maritime Engineering 163, 31-42. 
446 Pontee N.I,, Parsons, A., 2012. Adaptation as part of sustainable shoreline management in England and Wales. Maritime Engineering 165, 113-130.

Quintino, V., Sangiorgio, F., Ricardo, F., Mamede, R., Pires, A., Freitas, R., Rodrigues, A.M., Basset, A., 2009. In situ experimental study of reed leaf decomposition along a full salinity gradient. Estuarine, Coastal and Shelf Science 85, 497-506.

Roache, M.C., Bailey, P.C., Boon, P.I., 2006. Effects of salinity on the decay of the freshwater macrophyte, Triglochin procerum. Aquatic Botany 84, 45-52.

Sangiorgio, F., Basset, A., Pinna, M., Sabetta, L., Abbiati, M., Ponti, M., Minocci, M., Orfanidis, S., Arvanitidis, C., Nicolaidou, A., Moncheva, S., Trayanova, A., Georgescu, L., Dragan, S., Beqiraj, S., Koutsoubas, D., Evagelopoulos, A., 2008. Environmental factors affecting Phragmites australis litter decomposition in Mediterranean and Black Sea transitional waters. Aquatic Conservation: Marine and Freshwater Ecosystems 18, 16-26.

Sheehan, E.V., Coleman, R.A., Thompson, R.C., Attrill, M.J., 2010. Crab-tiling reduces the diversity of estuarine infauna. Marine Ecology Progress Series 411, 137-148.

Tate, A.S., Battaglia, L.L., 2013. Community disassembly and reassembly following experimental storm surge and wrack application. Journal of Vegetation Science

464 Telesh, I.V., Khlebovich, V.V., 2010. Principal processes within the estuarine salinity 465 gradient: A review. Marine Pollution Bulletin 61, 149-155.

466 Tenore, K.R., Hanson, R.B., 1980. Availability of detritus of different types and ages to a polychaete macroconsumer Capitella capitata. Limnology and Oceanography $25,553-558$. 
469 Venice System, 1959. Final resolution of the symposium on the classification of brackish waters. Archives of Oceanography and Limnology 11(suppl.), 243-248.

471 Wong, J.X.W., Van Colen, C., Airoldi, L., 2015. Nutrient levels modify saltmarsh responses to increased inundation in different soil types. Marine Environmental Research 104, 37-46.

474 Zanuttigh, B., 2011. Coastal flood protection: What perspective in a changing climate? The THESEUS approach. Environmental Science \& Policy 14, 845-863.

Zappa, G., Shaffrey, L.C., Hodges, K.I., Sansom, P.G., Stephenson, D.B., 2013. A Multimodel Assessment of Future Projections of North Atlantic and European Extratropical Cyclones in the CMIP5 Climate Models. Journal of Climate 26, $5846-5862$.

480

481 Appendix

482 Table A.1. List of the taxa detected at the Freshwater (Fw), Low salinity (Lo) and High 483 salinity (Hi) habitat (*: presence; blank: absence). 


\begin{tabular}{|c|c|c|c|}
\hline Taxa & Fw & Lo & $\mathrm{Hi}$ \\
\hline Ancylidae & * & & \\
\hline Arachnidae & * & * & \\
\hline Asellus sp. & * & * & \\
\hline Brachycentridae $(\mathrm{J})$ & * & & \\
\hline Carcinus sp. & & * & * \\
\hline Carcinus sp. (J) & & * & * \\
\hline Chironomidae $(\mathrm{J})$ & * & * & * \\
\hline Corophium sp. & & & * \\
\hline Dytiscidae (J) & * & & \\
\hline Elmidae & * & * & \\
\hline Elmidae (J) & * & * & \\
\hline Ephemerellidae (J) & * & & \\
\hline Gammarus pulex & * & & \\
\hline Gammarus zaddachi & & * & * \\
\hline Goeridae (J) & * & * & \\
\hline Gyrinidae (J) & * & & \\
\hline Hydraenidae $(\mathrm{J})$ & * & & \\
\hline Hydrobiidae & * & * & * \\
\hline Jaera sp. & & * & * \\
\hline Lepidostomatidae (J) & * & * & \\
\hline Leptoceridae (J) & * & & * \\
\hline Leptophlebiidae (J) & * & & \\
\hline Leuctridae $(\mathrm{J})$ & * & & \\
\hline Limnephilidae (J) & * & & \\
\hline Nemouridae $(\mathrm{J})$ & * & & \\
\hline Nereidae & & * & * \\
\hline Neritidae & * & & \\
\hline Oligochaeta & * & * & * \\
\hline Philopotamidae (J) & * & & \\
\hline Platyhelminthes & * & & \\
\hline Polycentropodidae (J) & * & & \\
\hline Rhyacophilidae (J) & * & & \\
\hline Sericostomatidae $(\mathrm{J})$ & * & & \\
\hline Sphaeroma sp. & & * & * \\
\hline Tineidae & * & & * \\
\hline
\end{tabular}

